\title{
BIG DATA PROCESSING AND ANALYSIS USING MULTI-TEMPORAL SENTINEL 1 DATA TO MANAGE FLOODS IN NORTH OF MOROCCO
}

\author{
Meriem LAHSAINI, Hassan TABYAOUI ${ }^{1}$, Fatima EL HAMMICHI \\ Natural Resources and Environment Laboratory, Sidi Mohamed Ben Abdellah University, Polydisciplinary Faculty of Taza, \\ Morocco \\ meriam.lahsaini@usmba.ac.ma, hassan.tabyaoui@usmba.ac.ma, fatima.elhammichi@usmba.ac.ma
}

KEY WORDS: Sentinel 1, SAR Radar images, Earth Observation, Flood mapping, Morocco

\begin{abstract}
:
Floods are the natural hazards that produce the highest number of casualties and material damage in the Western Mediterranean, especially in Morocco. An improvement in flood risk assessment and study of a possible increase in flooding occurrence are therefore needed. Earth Observation big data such as the ones acquired by the Copernicus programme are providing unprecedented opportunities to detect changes and assess economic impacts in case of disasters. This article present the different results obtained by the multi-temporal methods using the Synthetic Aperture Radar images. The spaceborne Synthetic Aperture Radar (SAR) systems are suitable tools for flood mapping thanks to their daytime and nighttime and almost all-weather imaging capability, in addition to their sensitivity to surface roughness and to Flood monitoring. The method has been developed to exploit Sentinel-1 data. It has been tested for the 2018 flood of Tetouan (Morocco).
\end{abstract}

\section{INTRODUCTION}

Floods are one of the most common natural disasters occurring in many parts of the world every year, it's becoming an international issue. They have been a recurrent phenomenon in Morocco and cause huge losses to lives, properties, livelihood systems, infrastructure and public utilities. Flood damage tends to increase over time due to socio-economic development, population density, development, and the effect of climate change. An improvement in flood risk assessment and study of a possible increase in flooding occurrence are therefore needed to disaster monitoring and EA Data exploitation.

Earth observation (EO) technology has provided highly useful information in flood management over the past few decades. In 2012, the International Data Corporation (IDC) released the 2020 Digital Universe report (Gantz and Reinsel, 2012), which stated that the total amount of data available will double every two years. Increasingly, there is a drive to observe the Earth in multi-scale, comprehensive, and real-time perspectives, and the capability of accessing global Earth observations information has been rapidly enhanced (Hua-Dong et al., 2015). The big EO data of ESA's Copernicus programme is helping to move towards an improved flood risk assessment for both emergency management (EM) and better infrastructure planning (Twele et al., 2016). Remote sensing data from synthetic aperture radar (SAR) sensors can be an efficient means of monitoring flood extent in large wetlands, as traditional in situ techniques are limited by access, cost, and logistics (Arnesen, A.S et al 2013). The main advantages of SAR data are its relative independence of atmospheric and illumination conditions, and the capability of mapping inundation under vegetated areas (Woodhouse, 2006). Sentinel-1 (S1), a constellation of two radar satellites operational since October 2014, can monitor the entire Earth every 6 days, giving an unprecedented opportunity to access a large number of archived scenes (Potin et al., 2015; Torres et al., 2012).
Numerous research studies have shown the contribution of remote sensing data from synthetic aperture radar (SAR) for the mapping of flood zones at different methodologies such as unsupervised classification, active contour models, CD and thresholding (Martinis et al., 2011; Horritt et al., 2001; Li et al., 2014; Hostache et al., 2012; Martinez and Le Toan, 2007; Pulvirenti et al., 2011; Pierdicca et al., 2013; Pulvirenti et al., 2013; Arnesen et al., 2013). We propose a methodology modified (Cian et al., 2018), it is based on the use of the Normalized Different Flood Index (NDFI). The index is based on the multi-temporal statistical analysis of two sets of images, one containing only the images before the event, and another one containing images both of the event and before the event. Through the computation of the NDFI, a change detection is performed, and flood maps are derived. The index highlights flooded areas and allows to easily separate flooded pixels by non-flooded ones by means of a constant threshold.

The objective of this work is to present a semi-automatic, fast and reliable method to manage flood in support of economic impact assessment methods for a rapid estimation of losses (and precise in case of high-resolution elevation data available).

\section{PROBLEM FORMULATION}

SAR-based techniques for flood detection include histogram thresholding or clustering (Inglada and Mercier 2007, Martinis et al 2009). While most methods use a single image to process the flood event, change detection can be used to provide reference brightness information (Inglada and Mercier 2007, Huang et al 2011, Gan et al 2012) and works well in coordination with other techniques such as histogram thresholding and segmentation. This methods (image thresholding) sets as flooded all the pixels with a radar backscatter lower than a certain threshold value (Mason et al.,

\footnotetext{
$1_{*}$ Tabyaoui Hassan
} 
2012a, 2012b; Pulvirenti et al., 2012; Schumann et al., 2010; Townsend, 2002), is computationally not demanding, provides reliable results and is ideal for rapid mapping. However, it is affected by sources of error typical of SAR flood mapping:

1) Atmospheric disturbances (Atlas and Moore, 1987; Danklmayer and Chandra, 2009a, 2009b; Jameson et al., 1997; Polverari et al., 2014);

2) Bragg resonance in presence of wind (Bragg, 1913; Schaber et al., 1997);

3) Double bounce due to emerging vegetation or buildings from the inundated area (Franceschetti et al., 2002; Hong and Wdowinski, 2014; van Zyl et al., 1987; Hajnsek et al., 2009);

4) Dry and smooth bare soil exhibiting backscatter similar to that of water surfaces (O'Grady et al., 2011);

5) Vegetation masking part of the flood;

6) Soil moisture content increasing radar backscattering and limiting flood detection in mixed pixel (Jackson et al., 1996; Paloscia et al., 2013; Quesney et al., 2000; Shoshany et al., 2000; Wagner et al., 1999); and

7) User-dependence of the parameters chosen to produce the map (Martinis et al., 2009).

CD techniques are interesting because they can overcome part of these limitations and can substantially improve the accuracy of flood maps (Matgen et al., 2011). In CD techniques, the selection of a suitable reference image is crucial (Hostache et al., 2012) to detect changes in radar backscattering due to floods (Liu et al., 2004; Lu et al., 2004) and avoid the risk of under estimating the extent of the event (Singh, 1989; Lunetta et al., 2004; Ulaby and Dobson, 1989). By selecting reference images sensed with the same acquisition geometry of the flood image, it is possible to discriminate areas of low backscattering from flooded ones (Giustarini et al., 2013). However, for practical reasons the first non-flood image found in the archive is usually employed as reference (Jones et al., 2009). Now, thanks to EO big data we have the possibility of statistically analyzing long image time-series and easily identify a more robust reference.

\section{METHODOLOGY}

We developed a method for flood mapping characterized by a novel approach to $\mathrm{CD}$; in particular, it is based on multitemporal series analysis and the computation of two new indices, i.e. the Normalized Difference Flood Index (NDFI) for highlighting flooded areas, and the Normalized Difference Flood in short Vegetation Index (NDFVI) for highlighting shallow water in short vegetation.

This paper, therefore, has two objectives:

1. Easy threshold selection through the use of normalized indices;

2. and Capability of outlining shallow water in short vegetation in addition to open-land flooded areas using Snap logiciel;

We first present the implemented technique, which consists in the computation of the abovementioned NDFI and NDFVI, followed by thresholding and post-classification. Then, we present two another classification methods to validate our methodology.

As summarized in Fig. 1, two SAR multi-temporal series are created: one containing only reference images and one containing also images of the flood under investigation. The two stacks are first radiometrically calibrated and terrain corrected. Statistical analysis of the backscattering $\sigma 0$ of each pixel is then performed throughout the whole multi-temporal series. For each pixel, we calculate the minimum, maximum and mean, for both the stack of reference images and the one also including the flood scenes Fig 3 and Fig 4.

The maps obtained after the thresholding are then filtered following the scheme in Fig. 1 to reduce two sources of errors. Firstly, to reduce the effect of speckle. Secondly, all clusters smaller than 10 pixels are excluded to reduce spurious flooded areas. The same post-processing steps are applied to all the different datasets used in this analysis.

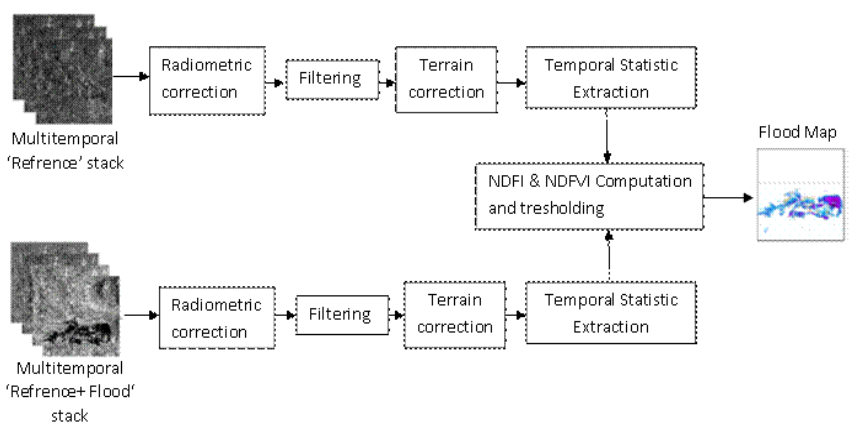

Figure 1. The methodology proposed consists in creating two stacks of images: one containing only reference images and one containing also images of the flood under investigation. The two stacks are then radiometrically calibrated and terrain corrected. Temporal statistics are extracted to compute the Normalized Difference Flood Index (to highlight temporary open water bodies) and the Normalized Difference Flood in Vegetated areas Index (to highlight shallow water in short vegetation). A threshold is finally applied to the indices values to extract only flooded areas. Additional filtering is applied to remove spurious cluster of pixels

\section{CASE STUDY}

The watershed of Oued Martil belongs to the Rifain domain. It is limited to the North by strings overlooking the Strait from Gibraltar, to the West by the plains of Gharb, to the south by the Rif high and to the East by the Mediterranean sea, It is located geographically between the two parallels $35.2^{\circ}$ and $35.8^{\circ} \mathrm{N}$, and the two meridians $5.6^{\circ}$ and $5.8^{\circ} \mathrm{W}$ (Fig. 1).

The Martil Basin is one of the Mediterranean basins that is characterized by a relatively large area and varied morphology. Its surface is of $1126 \mathrm{~km}^{2}$ corresponding to a perimeter of 183 $\mathrm{km}$. The basin, depending on the stations existing, is subdivided into 8 major sub-watersheds.

The altitudes and slopes of the Martil basin are very variable because of the position between the Rif chain and the sea Mediterranean. Indeed, the altitudes vary between $0 \mathrm{~m}$ on the coast and the plain at $1782 \mathrm{~m}$ at the extreme south of the sub basin of Kebir and the average altitude is of the order of $424 \mathrm{~m}$. Geologically, the litho-stratigraphic characters of the Rif chain are well represented. It is indicated by the overlap of several thrust sheets (flyschs) forming the ridge line above the marly unit of Tangier. The watershed of Martil, object of this study, is composed of two zones: 
The International Archives of the Photogrammetry, Remote Sensing and Spatial Information Sciences, Volume XLII-4/W16, 2019 6th International Conference on Geomatics and Geospatial Technology (GGT 2019), 1-3 October 2019, Kuala Lumpur, Malaysia

The upstream zone formed by Paleozoic lands located at the eastern end of the watershed and whose peaks do not exceed not the 400 meters above sea level. This zone also includes the flysch hills located at the western end of the basin slope and which correspond to the low mountains of the unit of Tangier whose impermeable material is of nature marly or marnoschisteuse.

The downstream zone of the basin corresponds to the plain of Oued Martil; it is a flood zone. The lithological variety of the watershed of Martil allowed the development of a rather large soil mosaic formed by soils little evolved hydromorphic and lithosols.

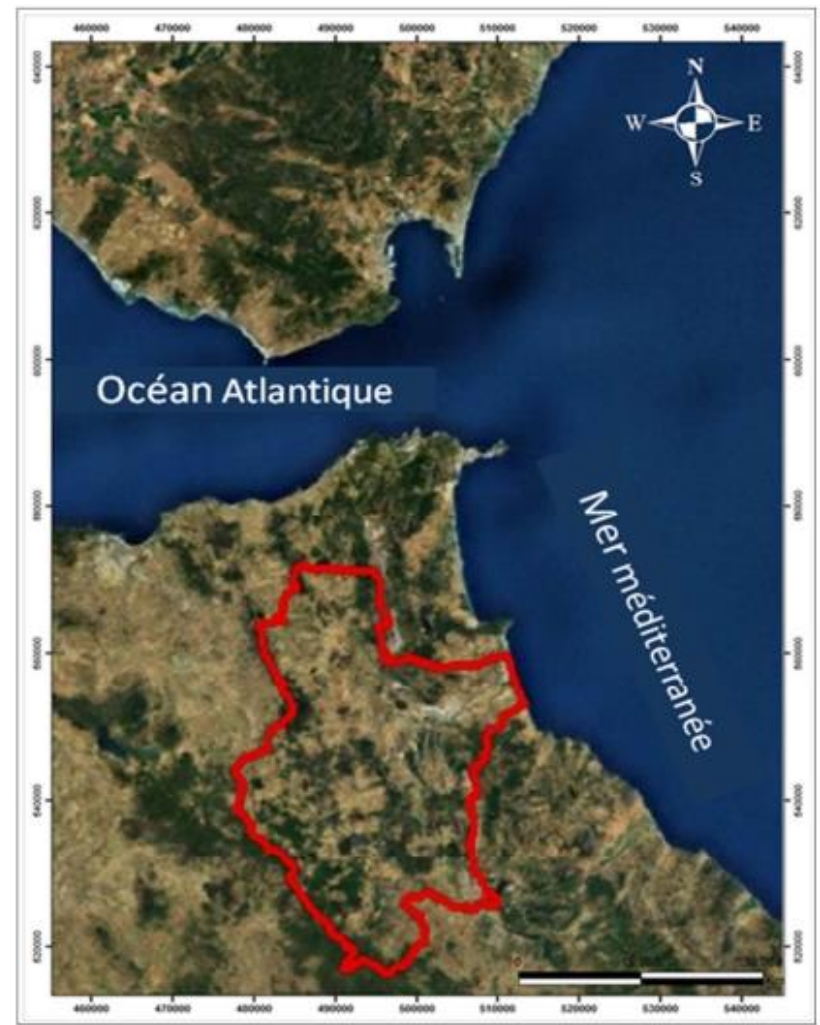

Figure 2. Location of Martil Basin

\section{RESULT DISCUSSION}

The new method we proposed aim at exploiting new big EO data. It is especially designed for using $\mathrm{S} 1$ data. A statistical analysis on a large amount of reference images gives more precise information about prevent conditions and allows a much more robust and precise detection of changes when a flood occurs. This was shown in our case studied presented, in particular for Morocco where S1 data were used.

We have two flood maps were produced for this flood event at different resolutions, precisions and coverage. The results are shown in Fig. 2, 3 and 4. The first image shows the S 1 images derived for the area of Tetouan on Febrery 20 and on March, 5 using $S 1$ (Fig. 2). From these images we can appreciate the evolution of the event and the different resolution of the products.

The results show a very good agreement (blue), the areas declared flooded only by the proposed method (light blue). Figure 7 confirms that there is an overflow but also shows how the proposed methods signal a wider flooded area. This is partially explained by the analysis of Fig.6, which shows a reference image for comparison with flooded image.

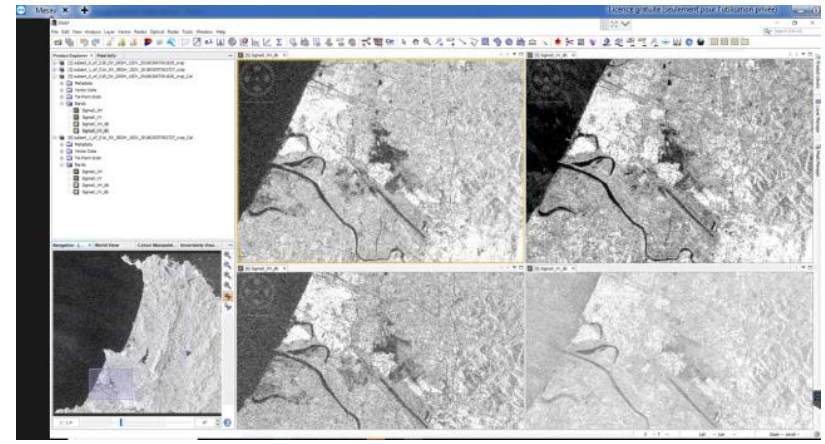

Figure 3. Results of using S1 SAR data. Two stacks are radiometrically calibrated.

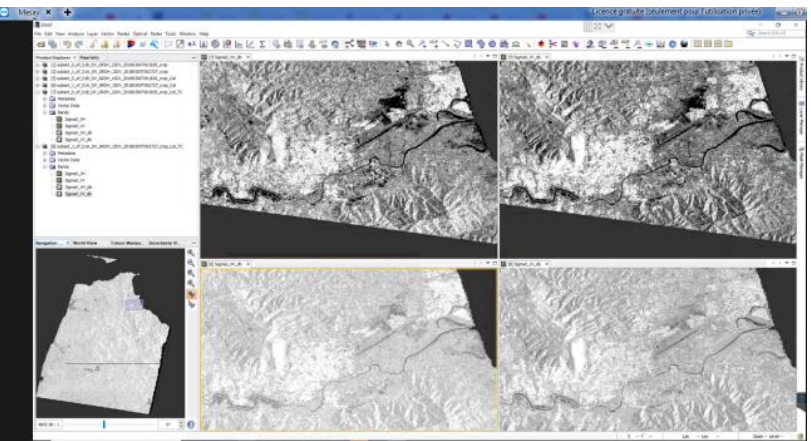

Figure 4. Results of using S1 SAR data. Two stacks are corrected geometrically.

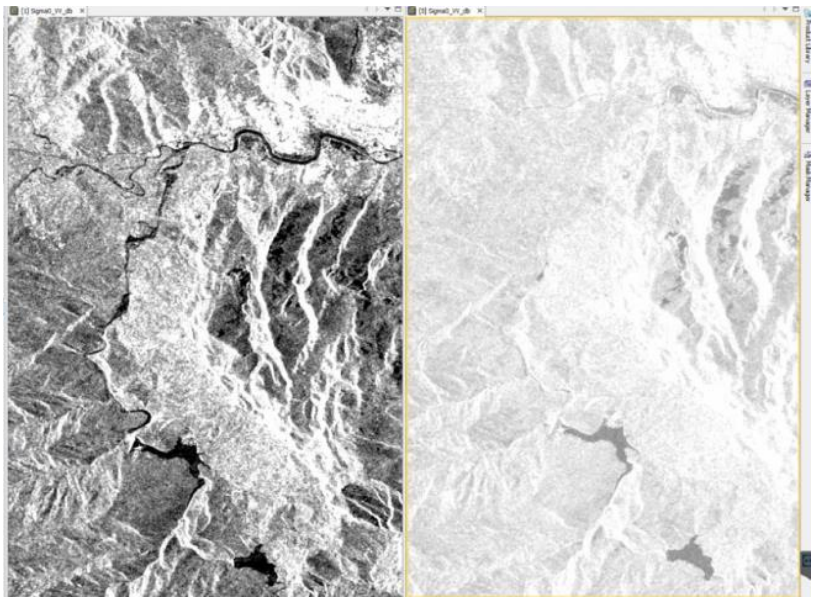

Figure 5. Results of the cross-comparison using S1 SAR. 




Figure 6. Results of using S 1 SAR data.

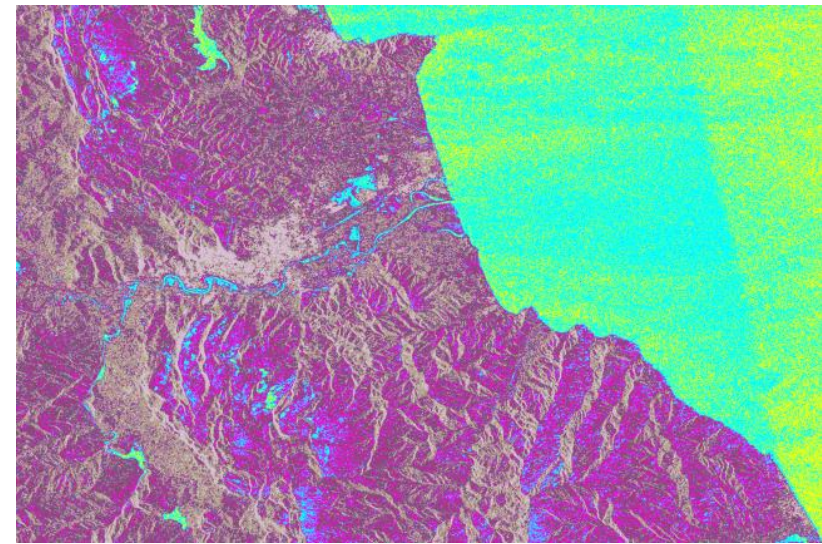

Figure 7. Results of Flooding are using S1 SAR data.

\section{CONCLUSION}

In this study, we presented a methodology for flood mapping based on free satellite data. In particular, we used data from Sentinel-1 and processed it with open-source software basedmethods easily carrying out also by non-remote sensing expert community. We tested our methodology over an areas recently hit by flood, the Tetouan city, North of Morocco, flooded in Mars 5, 2018.

This method based on time-series statistical analysis is proposed for flood mapping with the aim of exploiting the big EO data coming from the new Sentinel 1 constellation. Two indices are proposed for mapping flooded areas: the Normalized Difference Flood Index (NDFI), for mapping open water and the Normalized Difference Flood in Vegetation Index (NDFVI) for mapping shallow water in short vegetation.
Nevertheless there are still some limitations. The use of old SAR data prior to 2018, which usually are sparse and acquired with different geometries, showed to be more complicated and required more filtering steps even though precise results were obtained. In urban areas we could not obtain good results. The resolution of S1 did not allow for detecting changes using only radar intensity and at the moment of this analysis no Single Look Complex data were available on the areas considered in this paper and it remains a possibility for further

\section{ABBREVIATIONS}

$\begin{array}{ll}\text { CD } & \text { Change Detection } \\ \text { EO } & \text { Earth Observation } \\ \text { SAR } & \text { Synthetic Aperture Radar } \\ \text { S1 } & \text { Sentinel 1 } \\ \text { NDFVI } & \begin{array}{l}\text { Normalized Difference Flood in Vegetation } \\ \text { Index }\end{array} \\ \text { NDFI } & \text { Normalized Difference Flood Index }\end{array}$

\section{REFERENCES}

Arnesen, A.S., Silva, T.S.F., Hess, L.L., Novo, E.M.L.M., Rudorff, C.M., Chapman, B.D., McDonald, K.C., 2013. Monitoring flood extent in the lower Amazon River floodplain using ALOS/PALSAR ScanSAR images. Remote Sens. Environ. 130, 51-61.

http://dx.doi.org/10.1016/j.rse.2012.10.035

Atlas, D., Moore, R.K., 1987. The measurement of precipitation with synthetic aperture radar. J. Atmos. Ocean. Technol. 4 (3), 368-376.

http://dx.doi.org/10.1175/15200426(1987)004<0368:TMOPWS $>2.0 . \mathrm{CO} ; 2$

Franceschetti, G., Iodice, A., Riccio, D., 2002. A canonical problem in electromagnetic backscattering from buildings. IEEE Trans. Geosci. Remote Sens. 40 (8), 1787-1801. http://dx.doi.org/10.1109/TGRS.2002.802459

Lunetta, R.S., Johnson, D.M., Lyon, J.G., Crotwell, J., 2004. Impacts of imagery temporal frequency on land-cover change detection monitoring. Remote Sens. Environ. 89 (4), 444-454. http://dx.doi.org/10.1016/j.rse.2003.10.022

Hua-Dong, G., Li, Z., Lan-Wei, Z., 2015. Earth observation big data for climate change research. Adv. Clim. Chang. Res. 6 (2), 108-117. http://dx.doi.org/10.1016/j.accre.2015.09.007.

Gantz, J., Reinsel, D., 2012. The Digital Universe IN 2020: Big Data, Bigger Digital Shadows, and Biggest Growth in the Far East. IDC Analyze the Future, Framingham.

Twele, A., Cao, W., Plank, S., Martinis, S., 2016. Sentinel-1based flood mapping: a fully automated processing chain. Int. J. $\begin{array}{llll}\text { Remote } & \text { Sens. } & 37 & \text { (13), }\end{array}$ http://dx.doi.org/10.1080/01431161.2016.1192304

Ulaby, F.T., Dobson, M.C., 1989. Handbook of Radar Scattering Statistics for Terrain. Data Base (Vol. 1). 
Potin, P., Rosich, B., Miranda, N., Grimont, P., Bargellini, P., Monjoux, E., ... Krassenburg, M., 2015. Sentinel-1 mission status. In: International Geoscience and Remote Sensing Symposium (IGARSS) (Vol. 2015-Novem), pp. 2820-2823. http://dx.doi.org/10.1109/IGARSS.2015.7326401

Paloscia, S., Pettinato, S., Santi, E., Notarnicola, C., Pasolli, L., Reppucci, A., 2013. Soil moisture mapping using Sentinel-1 images: algorithm and preliminary validation. Remote Sens. Environ. 134, 234-248.

http://dx.doi.org/10.1016/j.rse.2013.02.027

Polverari, F., Mori, S., Pierdicca, N., Marzano, F.S., Pulvirenti, L., 2014. Precipitation signature on side-looking aperture radar imaging: sensitivity analysis to surface effects at $\mathrm{C}, \mathrm{X}$ and $\mathrm{Ku}$ band. In: European Microwave Week 2014: "Connecting the Future", EuMW 2014 - Conference Proceedings; EuRAD 2014: 11th European Radar Conference, pp. 197-200. http://dx.doi.org/10.1109/EuRAD.2014.6991241

Quesney, A., Le Hégarat-Mascle, S., Taconet, O., VidalMadjar, D., Wigneron, J.P., Loumagne, C., Normand, M., 2000. Estimation of watershed soil moisture index from ERS/SAR data. Remote Sens. Environ. 72 (3), 290-303. http://dx.doi.org/10.1016/S0034-4257(99)00102-9

Torres, R., Snoeij, P., Geudtner, D., Bibby, D., Davidson, M., Attema, E., ... Rostan, F., 2012. GMES Sentinel-1 mission. Remote Sens. Environ. 120, 9-24.

http://dx.doi.org/10.1016/j.rse.2011.05.028

Martinis, S., Twele, A., Voigt, S., 2011. Unsupervised extraction of flood-induced backscatter changes in SAR data using markov image modeling on irregular graphs. IEEE Trans. Geosci. Remote Sens. 49, 251-263. http://dx.doi.org/10.1109/TGRS.2010.2052816

Horritt, M.S., Mason, D.C., Luckman, a. J., 2001. Flood boundary delineation from synthetic aperture radar imagery using a statistical active contour model. Int. J. Remote Sens. 22 (October 2014), 2489-2507.

http://dx.doi.org/10.1080/01431160152497691

Hostache, R., Matgen, P., Wagner, W., 2012. Change detection approaches for flood extent mapping: how to select the most adequate reference image from online archives? Int. J. Appl. Earth Obs. Geoinf. 19 (1), 205-213. http://dx.doi.org/10.1016/j.jag. 2012.05.003

Jones, K., Lanthier, Y., van der Voet, P., van Valkengoed, E., Taylor, D., Fernandez-Prieto, D., 2009. Monitoring and assessment of wetlands using Earth observation: the GlobWetland project. J. Environ. Manag. 90, 2154-2169. http://dx.doi.org/10.1016/j.jenvman.2007.07.037.

Jackson, T.J., Schmugge, J., Engman, E.T., 1996. Remote sensing applications to hydrology: soil moisture. Hydrol. Sci. J. 41 (4), 517-530. http://dx.doi.org/10.1080/02626669609491523

Li, N., Wang, R., Liu, Y., Du, K., Chen, J., Deng, Y., 2014. Robust river boundaries extraction of dammed lakes in mountain areas after Wenchuan earthquake from high Li, N., Wang, R., Liu, Y., Du, K., Chen, J., Deng, Y., 2014. Robust river boundaries extraction of dammed lakes in mountain areas after Wenchuan earthquake from high

Hostache, R., Matgen, P., Wagner, W., 2012. Change detection approaches for flood extent mapping: how to select the most adequate reference image from online archives? Int. J. Appl. Earth Obs. Geoinf. 19 (1), 205-213. http://dx.doi.org/10.1016/j.jag.2012.05.003

Martinez, J.M., Le Toan, T., 2007. Mapping of flood dynamics and spatial distribution of vegetation in the Amazon floodplain using multitemporal SAR data. Remote Sens. Environ. 108 (3), 209-223. http://dx.doi.org/10.1016/j.rse.2006.11.012

Matgen, P., Hostache, R., Schumann, G., Pfister, L., Hoffmann, L., Savenije, H.H.G., 2011. Towards an automated SAR-based flood monitoring system: lessons learned from two case studies. Phys. Chem. Earth 36 (7-8), 241-252. http://dx.doi.org/10.1016/j.pce.2010.12.009

O'Grady, D., Leblanc, M., Gillieson, D., 2011. Use of ENVISAT ASAR Global Monitoring Mode to complement optical data in the mapping of rapid broad-scale flooding in Pakistan. Hydrol. Earth Syst. Sci. 15 (11), 3475-3494. http://dx.doi.org/10.5194/hess-15-3475-2011

Singh, A., 1989. Review article digital change detection techniques using remotely-sensed data. Int. J. Remote Sens. 10 (6), 989-1003. http://dx.doi.org/10.1080/01431168908903939

W., Wagner, Lemoine, G., Rott, H., 1999. A method for estimating soil moisture from ERS scatterometer and soil data. Remote Sens. Environ. 70 (2), 191-207.

Ward, D.P., Petty, A., Setterfield, S.A., Douglas, M.M., Ferdinands, K., Hamilton, S.K., Phinn, S., 2014. Floodplain inundation and vegetation dynamics in the Alligator Rivers region (Kakadu) of northern Australia assessed using optical and radar remote sensing. Remote Sens. Environ. 147, 43-55. http://dx.doi.org/10.1016/j.rse.2014.02.009

Wilson, B.A., Rashid, H., 2005. Monitoring the 1997 flood in the Red River valley. Can.Geogr. 49 (1), 100-109

Revised August 2019 